Delft University of Technology

\title{
Homogenization of the terrestrial water cycle
}

Levia, Delphis F.; Creed, Irena F.; Hannah, David M.; Nanko, Kazuki; Boyer, Elizabeth W.; Carlyle-Moses, Darryl E.; van de Giesen, Nick; Grasso, Domenico; Guswa, Andrew J.; More Authors

DOI

10.1038/s41561-020-0641-y

Publication date

2020

Document Version

Final published version

Published in

Nature Geoscience

\section{Citation (APA)}

Levia, D. F., Creed, I. F., Hannah, D. M., Nanko, K., Boyer, E. W., Carlyle-Moses, D. E., van de Giesen, N., Grasso, D., Guswa, A. J., \& More Authors (2020). Homogenization of the terrestrial water cycle. Nature Geoscience, 13, 656-658. https://doi.org/10.1038/s41561-020-0641-y

\section{Important note}

To cite this publication, please use the final published version (if applicable).

Please check the document version above.

\section{Copyright}

Other than for strictly personal use, it is not permitted to download, forward or distribute the text or part of it, without the consent of the author(s) and/or copyright holder(s), unless the work is under an open content license such as Creative Commons.

Takedown policy

Please contact us and provide details if you believe this document breaches copyrights.

We will remove access to the work immediately and investigate your claim. 
Green Open Access added to TU Delft Institutional Repository

'You share, we take care!' - Taverne project

https://www.openaccess.nl/en/you-share-we-take-care

Otherwise as indicated in the copyright section: the publisher is the copyright holder of this work and the author uses the Dutch legislation to make this work public. 


\section{Homogenization of the terrestrial water cycle}

Land-use and land-cover changes are accelerating. Such changes can homogenize the water cycle and undermine planetary resilience. Policymakers and practitioners must consider water-vegetation interactions in their

land-management decisions.

Delphis F. Levia, Irena F. Creed, David M. Hannah, Kazuki Nanko, Elizabeth W. Boyer, Darryl E. Carlyle-Moses, Nick van de Giesen, Domenico Grasso, Andrew J. Guswa, Janice E. Hudson, Sean A. Hudson, Shin'ichi lida, Robert B. Jackson, Gabriel G. Katul, Tomo'omi Kumagai, Pilar Llorens, Flavio Lopes Ribeiro, Diane E. Pataki, Catherine A. Peters, Daniel Sanchez Carretero, John S. Selker, Doerthe Tetzlaff, Maciej Zalewski and Michael Bruen

$\mathrm{H}$ ydrological, ecological and human systems are interconnected.

Recognizing this, the United Nations declared 2018-2028 as the International Decade for Action on 'Water for Sustainable Development'. Likewise, the International Association of Hydrological Sciences designated 2013-2022 as the scientific decade of 'Panta Rhei - Everything Flows' to foster hydrological research into the human influence on the water cycle ${ }^{1}$. Yet, policies that alter land use and land cover to increase carbon sequestration and meet food, water and energy demands are altering the water cycle in ways that risk unintended global consequences. There are multi-faceted risks associated with large-scale, human-induced homogenization of land cover, such as the conversion of natural forests to monocultural plantations or crops $^{2}$. We must quantify how the resulting losses in plant diversity affect the water cycle and, in turn, planetary resilience to global change. We call on natural and social scientists alike to provide the evidence base needed to understand and sustainably manage the consequences of large-scale land-use and land-cover change for the water cycle and preserve the resilience of water-dependent ecosystems and society.

Our planet is under increasing stress, with some planetary boundaries that define the "safe operating space for humanity" already being crossed. Human activities on land are extending and intensifying: approximately four-fifths of the Earth's

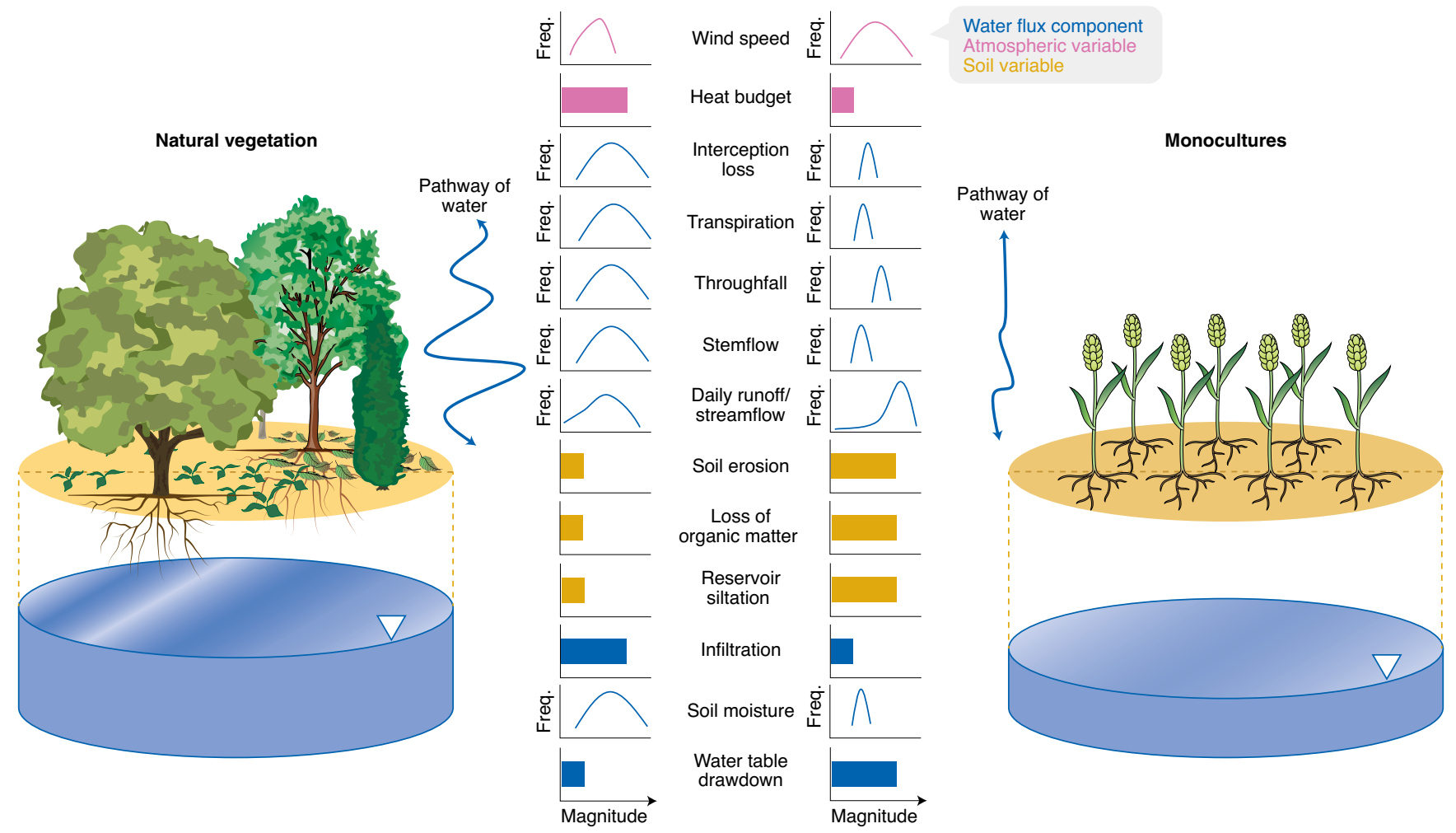

Fig. 1 | Conceptual diagrams showing the differences in the water cycle of natural vegetation and monocultures. Plots show the frequency distribution (lines) and relative magnitude (bars) of the hydrological fluxes (blue), atmospheric variables (pink) and soil processes (yellow). No specific scales are shown; magnitudes depend on region and specific vegetation. The vertical dotted yellow lines indicate the distance to the water table (white triangle). 
ice-free land surface has been directly impacted by humans, with forestry and agriculture active on about half of the human-modified land area as of 2007 (ref. ${ }^{4}$ ). The area of monocultures - agriculture, silviculture or grazing involving a single crop - is increasing, as is the yield per unit area of cropland. For example, the global coverage of forest plantations increased from 167.5 million ha in 1990 to 277.9 million ha by 2015 (ref. ${ }^{5}$ ). These land conversions are changing water demand: forest plantations with fast-growing, short-rotation species are likely to use more water compared to indigenous vegetation and older plantations $s^{6}$.

These land-use trends are poised to continue or even accelerate. Policies worldwide are being designed and implemented to optimize specific products (for example, food, water and energy) or specific functions (for example, carbon sequestration) that - if we are not careful will result in more uniform land use and land cover. Between 2001 and 2015, 27\% of the global forest loss was for agriculture, mining and energy infrastructure ${ }^{2}$. Meanwhile, global reforestation initiatives have been designed to combat climate change by sequestering carbon, including the Bonn Challenge that aims to restore 350 million ha of deforested and degraded land by 2030, and the Trillion Trees Partnership that aims to restore one trillion trees by 2050 - with the risk of creating uniform forests. Both deforestation and reforestation efforts seldom consider the consequences for the resilience of the water cycle to stressors. More research is needed to determine what is the right tree in the right place, especially under changing climate conditions, and more education and outreach are needed to ensure that the right trees really are planted in the right places.

Human-driven changes in land cover are leading to a more homogenized water cycle over vast regions of the planet. A homogenized water cycle is characterized by a narrowing of the range and variability of vegetation-atmosphere interactions that occur. The shift from natural or diverse vegetation mixes to planted monocultures can lead to more uniform patterns of transpiration, interception, evaporation, the routing of precipitation to the soil and groundwater recharge. This homogenization of the terrestrial water cycle can occur both spatially - for example, with the conversion of native forests with a mix of species to monocultures - and temporally - for example, with the conversion of mixed-age native forests to forests full of fast-growing trees of uniform age.

Figure 1 shows conceptually how the water cycle adjusts when naturally mixed vegetated land is replaced by monocultures. The lower diversity and more uniform canopy structure of monocultures lead to a more constrained and limited routing of water, as compared to the diverse hydrological functioning of a naturally vegetated landscape. The consequence is that monocultures are more vulnerable to hydroclimatic and ecological disturbances. For example, monocultures are less able to cope with climate extremes, such as droughts, leading to positive feedback loops where wetter climates become wetter and drier climates become drier, and these in turn are further exacerbated by climate change ${ }^{7}$.

Care is needed to prevent the world's overreliance on a few choice trees and crops $^{8}$ so as to avoid homogenization of the terrestrial water cycle. The short-term gains for climate mitigation delivered by planting swaths of uniform trees for carbon storage may be offset by the long-term losses caused by the hydrological consequences of lower resilience to environmental disturbances. For example, plant uniformity in agricultural landscapes that have replaced wetlands has been linked to increases in flood and drought frequencies and magnitudes, and deterioration of water quality, both of which place people at risk ${ }^{9}$. Furthermore, plant uniformity in forested areas has been linked to changes in precipitation recycling by altering the balance between local water storage and runoff and the contribution of evaporation within a region to precipitation elsewhere - with different consequences in different climatic zones for both downstream and downwind water supplies utilized by people ${ }^{10}$. Yet current international policymakers often consider forests largely in terms of the carbon cycle without consideration of the implications for the water cycle ${ }^{10}$.

Hydrological homogenization may influence the water cycle both directly by changing the quantities of water flowing, and indirectly by modifying water quality. For example, increased production of maize monocultures to meet US federal mandates for ethanol and biodiesel are projected to increase areas susceptible to groundwater nitrate contamination by $56-79 \%$ (ref. ${ }^{11}$ ). And increased production of tree plantations to meet the demand for wood can reduce, or even eliminate, streamflow and also lead to the salinization and acidification of soils in some conditions ${ }^{12}$.

Land-use policies and management need to take into account hydrological feedbacks to avoid the homogenization of the terrestrial water cycle and the resulting ramifications for human health and

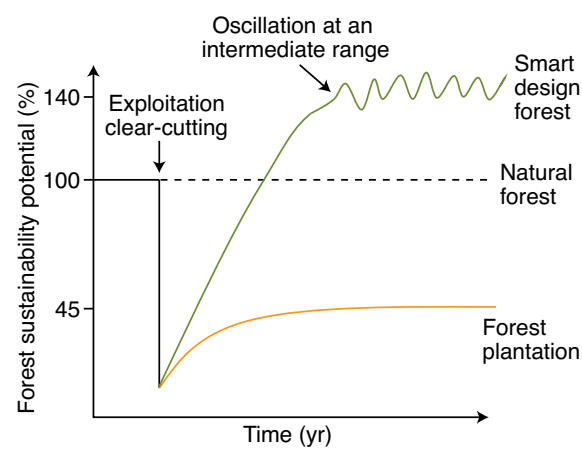

Fig. 2 | Forest sustainability potential over time.

Forest sustainability potential is defined, using the approach described in ref. ${ }^{14}$, as the stability of forest ecosystem structure and function and the resilience of the forest and associated ecosystem services to human and environmental disturbances. A baseline of $100 \%$ represents an undisturbed natural forest (dotted line). Clear-cutting of the forest (black line) results in a sudden drop in sustainability potential. For a monoculture forest, such as a plantation (orange line), forest sustainability potential is reduced due to simplified forest structure and function. For a diverse managed forest using smart design (green line), forest sustainability potential can be enhanced. In this case, the oscillation in forest sustainability potential is due to various management treatments (for example, tree felling) and succession stages in the intermediate time span ${ }^{15}$ within the step-wise progression of smart design.

prosperity. Policy and management options include so-called smart design in forestry and agriculture that aims to enhance species diversity. In the case of a managed forest, smart design involves planting trees with a range of (1) crown surface areas and crown architectures that affect water interception and flow through the forest canopy, (2) biophysical foliar traits that control transpiration and interception loss, (3) bark microrelief and textures that partly control water fluxes on and near tree trunks, and (4) leaf life spans and the structure and function of the plant vascular structure that influences transpiration.

Smart design to maximize each of the above forest properties would help to maintain heterogeneity of the water cycle and sustainability of vegetation, land and water resources (Fig. 2). For example, mixed forests and crops with species of differing leaf thicknesses and stomatal resistances to transpiration loss could be designed to better buffer drought and save water. The spatial scales meaningful for water management must be considered and whether these scales transcend jurisdictional 
boundaries and therefore require new forms of governance.

In addition to visible plant growth, below-ground properties of vegetation must be considered to protect the water cycle too. Compared to monocultures, diverse vegetation mixes have diverse rooting systems that can access a larger volume of soil and soil moisture. A diverse rooting system facilitates resilience to drought and optimizes the use of soil water and nutrients.

Going forward, scientific efforts are needed to pinpoint the hydrological functions that are most susceptible to homogenization in the conversion of natural vegetation to planted monocultures. A burgeoning suite of new sensor technologies for ever-finer scale measurements, including accelerometers for interception measurements and laser spectroscopy for the stable isotopes of water, are becoming more available $^{13}$. Such empirical evidence will also be vital to improve model projections of the impacts of landscape change on the terrestrial water cycle.

Current global trends in land-use change towards monocultures are risking a more homogeneous terrestrial water cycle with consequences for planetary resilience. Policymakers and practitioners should design forests and agricultural systems that embrace the differences among plant species to maintain the variation in the hydrological response of the land surface in both rural and urban areas. By recognizing, preserving or enhancing the nature-based resilience inherent in the diverse array of hydrological responses among plant species, we can provide better stewardship of the Earth's finite water resources.
Delphis F. Levia (D) 1,22凶, Irena F. Creed (D) 2,22, David M. Hannah (D)3, Kazuki Nanko (D)4, Elizabeth W. Boyer $\mathbb{D D}^{5}$,

Darryl E. Carlyle-Moses (D)6,

Nick van de Giesen (D)7, Domenico Grasso ${ }^{8}$, Andrew J. Guswa (D), Janice E. Hudson (D)', Sean A. Hudson (D)', Shin'ichi lida (D) 4 , Robert B. Jackson (D) 10, Gabriel G. Katul'1, Tomo'omi Kumagai (D) 12, Pilar Llorens (D)13 Flavio Lopes Ribeiro (D) 14, Diane E. Pataki (D) 15 Catherine A. Peters (D) 16

Daniel Sanchez Carretero (D) 17,

John S. Selker (D) ${ }^{18}$, Doerthe Tetzlaff(D) ${ }^{19}$, Maciej Zalewski (DD20 and Michael Bruen (D) 21 ${ }^{1}$ Department of Geography and Spatial Sciences, University of Delaware, Newark, DE, USA. ${ }^{2}$ School of Environment and Sustainability, University of Saskatchewan, Saskatoon, Saskatchewan, Canada. ${ }^{3}$ School of Geography, Earth and Environmental Science, University of Birmingham, Birmingham, UK. ${ }^{4}$ Department of Disaster Prevention, Meteorology and Hydrology, Forestry and Forest Products Research Institute, Tsukuba, Japan. ${ }^{5}$ Department of Ecosystem Science and Management, Pennsylvania State University, University Park, PA, USA. ${ }^{6}$ Department of Geography and Environmental Studies, Thompson Rivers University, Kamloops, British Columbia, Canada. ${ }^{7}$ Faculty of Civil Engineering and Geosciences, Delft University of Technology, Delft, Netherlands. ${ }^{8}$ Office of the Chancellor, University of Michigan- Dearborn, Dearborn, MI, USA. ${ }^{9}$ Picker Engineering Program, Smith College, Northampton, MA, USA. ${ }^{10}$ Department of Earth System Science, Woods Institute for the Environment, and Precourt Institute for Energy, Stanford University, Stanford, CA, USA. ${ }^{11}$ Nicholas School of the Environment, Duke University, Durham, NC, USA. ${ }^{12}$ Graduate School of Agricultural and Life Sciences, University of Tokyo, Tokyo, Japan. ${ }^{13}$ Institute of Environmental $\square$ Assessment and Water Research (IDAEA-CSIC),
Barcelona, Spain. ${ }^{14}$ Disaster Research Center, University of Delaware, Newark, DE, USA. ${ }^{15}$ School of Biological Sciences, University of Utah, Salt Lake City, UT, USA. ${ }^{16}$ Department of Civil and Environmental Engineering, Princeton University, Princeton, NJ, USA. ${ }^{17}$ Department of Civil and Environmental Engineering, University of Delaware, Newark, DE, USA. ${ }^{18}$ Department of Biological and Ecological Engineering, Oregon State University, Corvallis, OR, USA. ${ }^{19}$ Leibniz Institute of Freshwater Ecology and Inland Fisheries, Berlin, Germany. ${ }^{20}$ European Regional Center for Ecohydrology, UNESCO and Department of Applied Ecology, University of Lodz, Lodz, Poland. ${ }^{21}$ UCD School of Civil Engineering, University College Dublin, Dublin, Ireland. ${ }^{22}$ These authors contributed equally:

Delphis F. Levia, Irena F. Creed.

凶e-mail:dlevia@udel.edu

Published online: 21 September 2020

https://doi.org/10.1038/s41561-020-0641-y

References

1. McMillan, H. et al. Hydrol. Sci. J. 61, 1174-1191 (2016).

2. Curtis, P. G. et al. Science 361, 1108-1111 (2018).

3. Rockström, J. et al. Nature 461, 472-475 (2009).

4. Hooke, R. L. et al. GSA Today 22, 4-10 (2012).

5. Liu, C. et al. Glob. Ecol. Conserv. 15, e00419 (2018).

6. Calder, I. R. For. Ecol. Manag. 251, 110-120 (2007).

7. Huntington, T. G. J. Hydrol. 319, 83-95 (2006).

8. Foley, J. A. et al. Science 309, 570-574 (2005).

9. Millennium Ecosystem Assessment (World Resources Institute, 2005).

10. Creed, I. F. et al. Front. For. Glob. Change 2, 64 (2019).

11. Garcia, V. et al. Sci. Total Environ. 586, 16-24 (2017).

12. Jackson, R. B. et al. Science 310, 1944-1947 (2005).

13. Guswa, A. J. et al. Ecohydrology 13, e2208 (2020).

14. Zalewski, M. J. Hydrol. Eng. 20, A4014012 (2015).

15. Connell, J. H. Science 199, 1302-1310 (1978).

\section{Acknowledgements}

This paper stems from the Ettersburg Ecohydrology

Workshop (October 2018). Funding was provided by the

UNIDEL Foundation, Inc. and the University of Delaware.

Competing interests

The authors declare no competing interests.

\section{Arctic fires re-emerging}

Underground smouldering fires resurfaced early in 2020, contributing to the unprecedented wildfires that tore through the Arctic this spring and summer. An international effort is needed to manage a changing fire regime in the vulnerable Arctic.

\section{Jessica L. McCarty, Thomas E. L. Smith and Merritt R. Turetsky}

W ildfires are not a novel phenomenon in the Arctic; however, 2020's fire season began two months early and has been far more severe than usual. While increasing fire activity in boreal forests to the south ${ }^{1,2}$ and an unusually warm winter in the
Arctic $^{3}$ have led some to suggest that this uptick in wildfires was inevitable, there is still uncertainty about their source and their local and global impact. Here, we discuss how the wildfires in the Arctic are changing and how the input and expertise of local and Indigenous communities will be essential to determine whether this year is an anomaly or the beginning of a new fire regime.

\section{Early burning season}

Wildland fire experts generally believe that fires in the extreme early season in the 